\title{
The Body-Mass Index, Airflow Obstruction, Dyspnea, and Exercise Capacity Index Clinical Classification
}

National Cancer Institute

\section{Source}

National Cancer Institute. The Body-Mass Index, Airflow Obstruction, Dyspnea, and

Exercise Capacity Index Clinical Classification. NCI Thesaurus. Code C121006.

A standardized rating scale developed by Celli et al in 2004, which is a multidimensional grading system used to assess the respiratory and systemic expressions of COPD, and to predict the risk of death among patients with COPD. This instrument has a total possible values range from 0 to 10 , based on FEV1, body-mass index, the distance walked in six minutes, and the modified MRC dyspnea scale. 